\title{
"Cross" modalities: are the AMRAP, RFT and EMOM models applicable to health?
}

\section{Modalidades "Cross": Os Modelos AMRAP, RFT e EMOM são aplicáveis no contexto da Saúde?}

\author{
Marzo Edir Da Silva-Grigoletto \\ (D) https://orcid.org/0000-0003-3338-1359 \\ Juan Ramón Heredia-Elvar ${ }^{2}$ \\ (D) https://orcid.org/0000-0002-0840-0944 \\ Levy Anthony de Oliveira ${ }^{1}$ \\ (D) https://orcid.org/0000-0002-4220-551X
}

Abstract - Currently, training models based on the maximum number of repetitions/rounds or on the execution of a proposed task in the shortest possible time have been gaining ground among Physical Education professionals. However, in our opinion, these models have significant drawbacks that oppose their use in the health context. Thus, we provide an analysis of the problems related to the control and magnitude of the training load (volume and intensity), distribution, duration, and characteristics of the recovery intervals and, of course, the intrasession density. This analysis was made without having measured each of these proposals directly. It is based on the reflection of the dynamics of the efforts made and potential fatigue generated. We hope to be able to verify and provide accurate and reliable data that may support and confirm the hypothesis generated through this analysis.

Key words: Exercise; Healthy lifestyle; Physical education and training.

Resumo - Atualmente, os modelos de treinamento em que são executados o número máximo de repetiçôes/rounds ou se completa a tarefa proposta no menor tempo possivel têm sido muito utilizados por grande parte dos profissionais de Educação Física. Contudo, ao nosso ver, tais modelos possuem importantes inconvenientes que contrapóem sua utilização dentro do contexto da saúde. Assim, nós fornecemos uma análise dos problemas relacionados ao controle da magnitude da carga de treinamento (volume e intensidade), a distribuição, duração e características das recuperações e, logicamente, da densidade intra-sessão. Esta análise foi realizada sem ter medido diretamente cada uma dessas propostas e se baseia na lógica da dinâmica dos esforços realizados e da potencial fadiga gerada. Em breve, esperamos poder verificar e fornecer os dados especificos para confirmar esta análise.

Palavras-chave: Educação Física e treinamento; Estilo de vida saudável; Exercício fsico.
1 Universidade Federal de Sergipe. São Cristovão, SE. Brasil.

2 Instituto Internacional Ciencias Ejercicio Físico y Salud. Espanha.

Received: May 16, 2020 Accepted: July 20, 2020

How to cite this article Da Silva-Grigoletto ME, Heredia-Elvar JR, Oliveira LA. "Cross" modalities: are the AMRAP, RFT and EMOM models applicable to health? Rev Bras Cineantropom Desempenho Hum 2020, 22:e75400. DOl: http://dx.doi. org/10.1590/1980-0037.2020v22e75400

Copyright: This work is licensed under a Creative Commons Attribution 4.0 International License. 


\section{INTRODUCTION}

The "Cross" modalities are characterized by constantly varied functional movements, which may be performed at high intensity. This modality includes exercises from weightlifting and powerlifting (clean and jerk, snatch, deadlift), gymnastic and calisthenic exercises (pull-ups, muscle-ups, handstands) and cardiometabolic exercises (sprints, rowing, jump rope $)^{1,2}$. Other names have been used to refer to these modalities, when not associated with the CrossFit ${ }^{\oplus}$ brand, such as Functional Fitness, Extreme Conditioning Programs, Mixed Modalities Training, High Intensity Functional Training, Cross Training, among other modalities popularly called "Cross".

Usually, the CrossFit ${ }^{\oplus}$ session may be divided into three parts: warmup, skill, and WOD (Workout of the day). Warm-up is designed to prepare the body for more intense activity. This part of the session may be sub-divided into general and specific warm-up ${ }^{3}$. The technical part of the session (skill) has the purpose of technically preparing the practitioner for the movements to be performed in the WOD. The WOD is the main part of the training session, which may be based on time or task. In the first case, when the WOD is time-based, the training ends when the time limit is completed. In the second, when the WOD is based on the task, the training ends when the task is completed ${ }^{3}$.

Some models or types of sessions based on task or time have gained much popularity in training centers (including, often mistakenly called "method" by coaches), such as: performing the maximum number of repetitions or rounds (AMRAP, as many reps/rounds as possible), complete the proposed task in the shortest possible time (RFT, rounds for time) or at every one-minute interval (EMOM, every minute on the minute). In addition to these, there are rounds not for time (RNFT), a model with priority in the movement technique. A certain number of rounds are carried out without worrying about time. However, this model is less used. In general, these models have been prescribed covering an entire training session, which in our perception is not correct, since it refers to a model that may be used in only one of the three parts of the training session.

Thus, when we think of a strength training session aimed at improving health, we must consider providing the appropriate stimulus (dose) to achieve optimal adaptations. This stimulus (dose) must be precisely defined and controlled in each of its variables ${ }^{4}$ to ensure that training is safe and effective. In this perspective, the dose is fundamentally defined by two fundamental variables:

The intensity, which in strength training is defined as the degree of effort required by each unit of action (repetition) expressed by the mean propulsive velocity (MPV) achieved in the first repetition or the fastest repetition in each set of each exercise $e^{5,6}$.

The volume, which in strength training is defined as the degree of effort representing the total repetitions performed and expressed by the 
percentage of velocity loss achieved in each set of each exercise $\mathrm{e}^{5,6}$.

The degree of fatigue achieved in a session will depend on the intensity and volume developed in each selected exercise, the entire sets, as well as another variable: recovery. Recovery is defined as the time between repetitions in the same exercise or between different exercises that aims to promote a certain degree of regeneration to develop a new effort. This recovery is expressed in time value and may have passive (pause) or active characteristics.

In our view, an adequate training dose to improve health-related aspects should not lead to excessive fatigue situations, such as those found by Tibana et al. ${ }^{7}$ who found high lactate concentrations with averages equal to $17.8 \pm 4.9 \mathrm{mmol} \cdot \mathrm{L}^{-1}$ and $17.2 \pm 3.5 \mathrm{mmol} \cdot \mathrm{L}^{-1}$ immediately after performing two WODs on the RFT and AMRAP models, respectively. In another study, similar behaviour was observed evaluating lactate concentrations during each round, with an exercise protocol with 4 rounds in the all-out condition $^{8}$. Besides, a series of cases of excessive rhabdomyolysis have been reported after training in this condition ${ }^{9-11}$. Thus, it is likely that training in conditions of maximum effort (all-out), such as AMRAP, RFT, and EMOM, may cause adverse effects related to health.

Thus, we described the most used models in the "Cross" modalities and analyzed the problems related to the control and magnitude of the training load (volume and intensity), distribution, duration and characteristics of the recovery intervals and, logically, of the intra-session density (the relationship between the work done and rest). We emphasize that this analysis was performed without having measured each of these proposals directly. It is based on the reflection of the dynamics of the efforts made and potential fatigue generated. We hope to verify and provide accurate and reliable data that may support and confirm the hypothesis generated through this analysis.

\section{UNDERSTANDING THE MODELS}

\section{As many rounds/repetitions as possible (AMRAP)}

It is a type of WOD in which the objective is to complete the maximum number of repetitions or rounds within a predetermined time. This model is focused on time since the time to complete the training is fixed ${ }^{3}$. Thus, the magnitude of the load used (volume and intensity in each exercise) varies. The practitioner dictates the amount of work done ${ }^{3}$. An example of WOD in this model is the "CINDY", in which the objective is to perform the task (5 pull-ups, 10 push-ups, and 15 squats with no external load) in the highest number of rounds within 20 minutes $^{3}$. Another example is AMRAP of 20 minutes of $400 \mathrm{~m}$ of running, 15 pull-ups in $\mathrm{L}$, and 5 clean and jerk with $93 \mathrm{~kg}^{3}$. Other possible abbreviations for this model are FOR REPS, FOR ROUNDS OR REPS, and MAX REPS.

\section{Rounds for time (RFT)}

It is a model in which a certain number of movements are performed in 
the shortest possible time. This model has an emphasis on task ${ }^{3}$. The task is fixed, and the objective is to complete it as quickly as possible. In this model, the absolute load does not change. The time to complete it varies, depending on the practitioner. A WOD example in this model is the "FRAN", whose objective is to perform the task (21-15-9 repetitions of thrusthers with $43 \mathrm{~kg}$ and pull-ups without external load) as soon as possible $^{3}$. Another example is the "GRACE" which consists of performing 30 clean and jerks with $61 \mathrm{~kg}$ for men and $43 \mathrm{~kg}$ for women, in the shortest possible time ${ }^{3}$. Other possible abbreviations for this model are TFT, 4TIME, FOUR TIME, and AFAP.

\section{Every minute on the minute (EMOM)}

This model consists of performing a certain number of movements at each 1-minute interval. After performing the set within 60 seconds, it is possible to rest the rest of the time until the minute ends. An example of this type of WOD is the "CHELSEA", in which the objective is to perform the task (5 pull-ups, 10 push-ups, and 15 squats with only their body mass) every minute within the time of 30 minutes $^{3}$. Other possible abbreviations for this model are $\mathrm{E} 2 \mathrm{MOM}$ or $\mathrm{E} 3 \mathrm{MOM}$, which means every 2 or 3 minutes. Usually, this type of WOD is based on both time and task, since both are fixed $^{3}$. What varies between individuals is the amount of rest experienced every minute ${ }^{3}$. However, an exception is when a part of the minute is packed with a fixed task. Therefore, the rest is packed with the maximum number of repetitions of another task. For example, a 12-minute EMOM ( 6 rounds) wherein minute 1 there is a $200 \mathrm{~m}$ run and in minute 2,15 situps plus front plank for the remainder of the one-minute interval.

\section{ANALYSIS OF PROBLEMS RELATED TO EACH MODEL}

\section{As many rounds/repetitions as possible (AMRAP)}

In AMRAP, we observed that in strength exercises, the practitioner who must complete the maximum number of repetitions/rounds in the established time could perform each exercise at the highest possible execution velocity since the first repetition. Thus, those for whom the different absolute loads (body mass or external resistance) assume a lower relative intensity, in theory, will complete each exercise in less time. Besides, depending on the velocity loss they reach over the set time, they will perform a higher number of repetitions/rounds in the pre-defined total time. In this way, the subject who could initially perform better would be the one who trains with less relative intensity, being able to perform the exercises at a higher velocity and possibly with a lesser velocity loss in the set, compared to those who perform the same number of repetitions with the same absolute load, which represents a higher relative intensity.

If the subject decides to perform each repetition at a slower velocity than the maximum possible, to "regulate" the efforts and try to achieve a 
higher number of repetitions/rounds in a given period, we will find that the difficulty in estimating the intensity is even greater. With the situation that, for the same number of repetitions, the time under tension will be longer, with the consequent repercussions on fatigue, conditioning the possibilities of reaching higher velocities in successive sets, in addition to the potential training effects derived from this type of strategy $y^{12,13}$.

This organization type may also be performed, including recovery periods with different amounts and durations, both between repetitions and between sets and exercises. This strategic variation would impact the ability to maintain a certain level of performance over time. However, it will undoubtedly lead us to the fact that the results will be presented with different densities. Together with the considerations mentioned above, it still put us before the fact of the difficulty of knowing, with a certain degree of precision, which load magnitude was achieved in training by each participant. It is clear that, in this case, precise control of the degree of effort made by each participant is not possible.

\section{Rounds for time (RFT)}

In the RFT, the exercises are performed with the same absolute load, and the established number of repetitions must be performed in the shortest possible time. In this way, the participants start each exercise with the same absolute load (except in the case of body mass), which will typically have different relative intensities. As the number of repetitions is established and fixed, the velocity loss for each subject may differ; therefore, the degree of fatigue achieved will be different in most cases. This variation in the character of effort made will mean that, in general, those who make a character of less effort will obtain a better result, which usually implies that the average velocity achieved will be higher, so that the average relative intensity will be lower in those who complete the rounds in less time. Once again, we are faced with a proposal that is impossible to know, with a certain degree of precision, the degree of effort developed by each participant.

\section{Every minute on the minute (EMOM)}

In EMOM, we consider that it is necessary to perform a series of tasks in one minute, within a specific total time interval, for example, 10 or $30 \mathrm{~min}$. In this case, the subjects perform the tasks in such a minute and rest as long as they have available after completion; that is, whoever completes the proposed tasks more quickly will rest more. Again, we are faced with a problematic proposal to determine the relative intensity each subject is submitted in each training. We must also assume that the subjects will perform each task from the first repetition at the maximum possible velocity and that the person who completes the tasks in the shortest time is probably the proposed absolute load representing a lower relative intensity. Furthermore, it probably registers a lower velocity loss in the total number of repetitions performed, which implies that the degree of fatigue achieved is likely to be less. 
Interestingly, in these cases, a lower effort character and completing the round in less time will allow longer recovery time. Those individuals who probably reached a higher degree of fatigue and, therefore, used more time in the round, will restless compared to those who completed the tasks in less time and, therefore, will have more recovery time. Also, as the set proceeds, it is expected that the first repetition velocity will be lower, and the velocity loss in the set will be higher, which places the subject in progressively smaller recoveries as they progress in time. Logically, prolonging this approach presents a problematic strategy to justify from a healthy perspective.

We want to draw attention to some critical issues:

- It may not be appropriate to consider these proposals as "training methods" since, according to the dictionary of the Portuguese language Aurélio $^{14}$, a method is the "reason or planning that determines or organizes a certain activity; order". In the context of physical exercise, the method is related to the realization of two aspects ${ }^{5}$ :

i) The selection, organization, and distribution of the training programming variables (mainly volume, intensity, and recovery).

ii) The selection, organization, and order or sequence of the exercises chosen for the training session.

For this reason, the specification of the training method of each training unit must be defined and considered as a dependent component of the other components of the exercise dose (volume, intensity, recovery) and specified by the selection of exercises and order of execution of those established to achieve the defined objective. In most of these proposals, we see how these variables are not controlled or are not very precise (Box 1). It is relevant to observe how the relative intensity and recovery time are not defined. The latter variable is frequently left to "autoregulation" from the practitioner, which puts us before training that may not be programmed and defined with precision from which highly variable results may be expected.

\section{FINAL COMMENTS}

In these, as in most models within the "Cross" modalities, we observe that the subject makes an effort (determined number of repetitions) in the shortest possible time or makes the maximum possible effort (highest number of repetitions) for a given time. In both cases, the control of the relative load is practically impossible; therefore, it is not possible to call training something that is not known or dosed and that, in any case, will imply that, in general, a better result will be obtained by those who perform these tasks with an absolute load that assumes a lower relative load value. These models may be extremely detrimental for health in both cases, but especially in the second case, in which the maximum number of repetitions is performed in a given time, as this would imply a higher effort index ${ }^{15}$. 
Box 1. Control analysis of the leading training programming variables during the main WOD models.

\begin{tabular}{|c|c|c|c|}
\hline Organization & Intensity control & Volume control & Recovery control \\
\hline $\begin{array}{l}\text { AMRAP } \\
\text { As Many Rounds/ } \\
\text { Repetitions as } \\
\text { Possible }\end{array}$ & $\begin{array}{l}\text { - Pre-established absolute load, } \\
\text { usually unchanged throughout the } \\
\text { set in each exercise; } \\
\text { - No precise control of the relative } \\
\text { intensity of each practitioner in } \\
\text { each exercise; } \\
\text { - A tendency to perform each rep- } \\
\text { etition at the maximum possible } \\
\text { velocity. }\end{array}$ & $\begin{array}{l}\text { - Training duration (time) pre- } \\
\text { established; } \\
\text { - Number of exercises pre-estab- } \\
\text { lished; } \\
\text { - Number of repetitions pre- } \\
\text { established; } \\
\text { - Number of sets varies according } \\
\text { to the current performance capac- } \\
\text { ity of each subject; } \\
\text { - Velocity loss increases over each } \\
\text { set. Lack of definition and control. }\end{array}$ & $\begin{array}{l}\text { - Individual possibility, at the } \\
\text { individual's discretion, to manage } \\
\text { intra-set, inter-set and exercise } \\
\text { recoveries; } \\
\text { - Variability and lack of control of } \\
\text { this variable. }\end{array}$ \\
\hline $\begin{array}{l}\text { RFT } \\
\text { Rounds for Time }\end{array}$ & $\begin{array}{l}\text { - Pre-established absolute load, } \\
\text { usually unchanged throughout the } \\
\text { set in each exercise; } \\
\text { - No precise control of the relative } \\
\text { intensity of each practitioner in } \\
\text { each exercise; } \\
\text { - A tendency to perform each rep- } \\
\text { etition at the maximum possible } \\
\text { velocity. }\end{array}$ & $\begin{array}{l}\text { - Total duration time not pre- } \\
\text { established; } \\
\text { - Objective to accomplish in the } \\
\text { shortest possible time (variability } \\
\text { and without definition); } \\
\text { - Number of exercises pre-estab- } \\
\text { lished; } \\
\text { - Number of sets pre-established; } \\
\text { - Velocity loss increases over each } \\
\text { set. Lack of definition and control. }\end{array}$ & $\begin{array}{l}\text { - Individual possibility, at the } \\
\text { individual's discretion, to manage } \\
\text { intra-set, inter-set and exercise } \\
\text { recoveries, although the need to } \\
\text { perform the task in the short- } \\
\text { est possible time conditions the } \\
\text { referred "self-regulation" to reduce } \\
\text { them to a minimum; } \\
\text { - Variability and lack of control of } \\
\text { this variable. }\end{array}$ \\
\hline $\begin{array}{l}\text { EMOM } \\
\text { Every Minute on } \\
\text { the Minute }\end{array}$ & $\begin{array}{l}\text { - Pre-established absolute load, } \\
\text { usually unchanged throughout the } \\
\text { set in each exercise; } \\
\text { - No precise control of the relative } \\
\text { intensity of each practitioner in } \\
\text { each exercise; } \\
\text { - A tendency to perform each rep- } \\
\text { etition at the maximum possible } \\
\text { velocity. }\end{array}$ & $\begin{array}{l}\text { - Training duration (time) pre- } \\
\text { established; } \\
\text { - Pre-established number of } \\
\text { exercises; } \\
\text { - Pre-established number of repeti- } \\
\text { tions; } \\
\text { - Number of sets pre-established; } \\
\text { - Velocity loss increases over each } \\
\text { set. Lack of definition and control. }\end{array}$ & $\begin{array}{l}\text { - Recovery time tends to be longer } \\
\text { for those who perform each set in } \\
\text { less time; } \\
\text { - The general trend will be that } \\
\text { the duration of the recovery } \\
\text { will be shorter as more sets are } \\
\text { performed. }\end{array}$ \\
\hline
\end{tabular}

This analysis implies that, instead of considering these "pseudomethods" as "High Intensity" models, perhaps we should consider them as "High Degree of Fatigue", because in most cases, whoever gets the best performance will have done it with a lower relative intensity. However, most practitioners will achieve a high degree of fatigue, due to the significant velocity loss that may be expected from these proposals and the low intra-set, inter-set and exercise recovery. This degree of fatigue in which the practitioner is located must be considered concerning its repercussions in the loss of control of the execution technique in many of the exercises and the potential increased risk of injury that this could entail, It questions the adequacy of these proposals in programs with health-related goals.

\section{COMPLIANCE WITH ETHICAL STANDARDS}

\section{Funding}

This research did not receive any specific grant from funding agencies in the public, commercial, or not-for-profit sectors. This study was funded by the authors.

\section{Ethical approval}

This research is in accordance with the standards set by the Declaration of Helsinki. 


\section{Conflict of interest statement}

The authors have no conflict of interests to declare.

\section{Author Contributions}

Conceived and designed the experiments: MEDSG, JRHE, and LAO. Performed the experiments: MEDSG, JRHE, and LAO. Analyzed the data: MEDSG, JRHE, and LAO. Contributed reagents/materials/analysis tools: MEDSG, JRHE, and LAO. Wrote the paper: MEDSG, JRHE, and LAO.

\section{REFERENCES}

1. Tibana RA, de Farias DL, Nascimento DC, Da Silva-Grigoletto ME, Prestes J. Relação da força muscular com o desempenho no levantamento olímpico em praticantes de CrossFit ${ }^{\circledR}$. Rev Andal Med Deporte 2018;11(2):84-8.

2. Tibana RA, de Sousa NMF. Are extreme conditioning programmes effective and safe? A narrative review of high-intensity functional training methods research paradigms and findings. BMJ Open Sport Exerc Med 2018;4(1):e000435.

3. CrossFit. Guia de treinamento de nível 1: Estados Unidos. 2002-2020; Disponível em: http://library.crossfit.com/free/pdf/CFJ_L1_TG_Portuguese.pdf [2020 mai 01].

4. Toigo M, Boutellier U. New fundamental resistance exercise determinants of molecular and cellular muscle adaptations. Eur J Appl Physiol 2006;97(6):643-63.

5. Heredia Elvar JR, Peña García-Orea G. El entrenamiento de la fuerza para la mejora de la condición física y la salud. Roquetas de Mar, Almería: Círculo rojo; 2019.

6. González Badillo JJ, Sánchez-Medina L, Pareja-Blanco F, Rodríguez-Rosell D. La velocidad de ejecución como referencia para la programación, control y evaluación del entrenamiento de fuerza. Murcia: Ergotech Consulting; 2017.

7. Tibana R, de Sousa N, Cunha G, Prestes J, Fett C, Gabbett T, et al. Validity of session rating perceived exertion method for quantifying internal training load during high-intensity functional training. Sports 2018;6(3):68.

8. Alsamir Tibana R, Manuel Frade de Sousa N, Prestes J, da Cunha Nascimento D, Ernesto C, Falk Neto JH, et al. Is perceived exertion a useful indicator of the metabolic and cardiovascular responses to a metabolic conditioning session of functional fitness? Sports 2019;7(7):161.

9. Hopkins BS, Li D, Svet M, Kesavabhotla K, Dahdaleh NS. CrossFit and rhabdomyolysis: A case series of 11 patients presenting at a single academic institution. J Sci Med Sport 2019;22(7):758-62.

10. Meyer M, Sundaram S, Schafhalter-Zoppoth I. Exertional and crossfit-induced rhabdomyolysis. Clin J Sport Med 2018;28(6):e92-4.

11. Tibana R, Sousa N, Cunha G, Prestes J, Navalta J, Voltarelli F. Exertional rhabdomyolysis after an extreme conditioning competition: a case report. Sports 2018;6(2):40.

12. Mazzetti S, Douglass M, Yocum A, Harber M. Effect of explosive versus slow contractions and exercise intensity on energy expenditure. Med Sci Sports Exerc 2007;39(8):1291-301.

13. González-Badillo JJ, Rodríguez-Rosell D, Sánchez-Medina L, Gorostiaga EM, Pareja-Blanco F. Maximal intended velocity training induces greater gains in bench press performance than deliberately slower half-velocity training. Eur J Sport Sci 2014;14(8):772-81.

14. Ferreira $\mathrm{AB}$ de $\mathrm{H}$, Ferreira MB, Anjos M dos. Dicionário Aurélio da língua portuguesa. 5a ed. Curitiba: Editora Positivo; 2010. 
15. Rodríguez-Rosell D, Yáñez-García JM, Torres-Torrelo J, Mora-Custodio R, Marques MC, González-Badillo JJ. Effort index as a novel variable for monitoring the level of effort during resistance exercises. J Strength Cond Res 2018;32(8):2139-53.

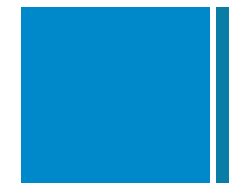

Corresponding author

Marzo Edir Da Silva-Grigoletto

321 Aricio Guimarães Fortes St., Aracaju, SE

49.037-060, BRA

Email: medg@ufs.br 